\title{
Interventional Pain Management in Multidisciplinary Chronic Pain Clinics: A Prospective Multicenter Cohort Study with One-Year Follow-Up
}

\author{
Cláudia Gouvinhas, ${ }^{1}$ Dalila Veiga, ${ }^{2}$ Liliane Mendonça, ${ }^{3}$ Rute Sampaio,,${ }^{1,4}$ \\ Luís Filipe Azevedo, ${ }^{3,5,6}$ and José Manuel Castro-Lopes ${ }^{1,3,4}$ \\ ${ }^{1}$ Department of Biomedicine, Faculty of Medicine, University of Porto, Porto, Portugal \\ ${ }^{2}$ Chronic Pain Center-Anesthesiology Department, Centro Hospitalar do Porto, Porto, Portugal \\ ${ }^{3}$ National Observatory for Pain (NOPain), Porto, Portugal \\ ${ }^{4}$ Institute for Molecular and Cell Biology (IBMC), University of Porto, Porto, Portugal \\ ${ }^{5}$ Department of Community Medicine, Information and Health Decision Sciences (MEDCIDS), Faculty of Medicine, \\ University of Porto, Porto, Portugal \\ ${ }^{6}$ Centre for Health Technology and Services Research (CINTESIS), University of Porto, Porto, Portugal
}

Correspondence should be addressed to Cláudia Gouvinhas; c.gouvinhas@gmail.com

Received 18 April 2017; Accepted 18 July 2017; Published 15 October 2017

Academic Editor: Robert L. Barkin

Copyright ( 2017 Cláudia Gouvinhas et al. This is an open access article distributed under the Creative Commons Attribution License, which permits unrestricted use, distribution, and reproduction in any medium, provided the original work is properly cited.

\begin{abstract}
Background. Interventional Pain Management (IPM) is performed in multidisciplinary chronic pain clinics (MCPC), including a range of invasive techniques to diagnose and treat chronic pain (CP) conditions. Current patterns of use of those techniques in MCPC have not yet been reported. Objective. We aimed to describe quantitatively and qualitatively the use of IPM and other therapeutic procedures performed on-site at four Portuguese MCPC. Methods. A prospective cohort study with one-year follow-up was performed in adult patients. A structured case report form was systematically completed at baseline and six and 12 months. Results. Among 808 patients referred to the MCPC, 17.2\% had been prescribed IPM. Patients with IPM were on average younger and had longer CP duration and lower levels of maximum pain and pain interference/disability. The three main diagnoses were low back pain $(n=28)$, postoperative CP, and knee pain $(n=16$ each). From 195 IPM prescribed, nerve blocks $(n=108)$, radiofrequency $(n=31)$, and viscosupplementation $(n=22)$ were the most prevalent. Some IPM techniques were only available in few MCPC. One MCPC did not provide IPM. Conclusions. IPM are seldom prescribed in Portuguese MCPC. Further studies on IPM safety and effectiveness are necessary for clear understanding the role of these techniques in CP management.
\end{abstract}

\section{Introduction}

Chronic pain $(\mathrm{CP})$ is a worldwide public health problem that causes a substantial burden on healthcare systems and society, taking into account its high prevalence, economic costs, and the quality of life impairment of the patients and their families. CP requires a multidisciplinary approach for its adequate assessment and management [1-5]. For more than twenty years, the International Association for the Study of Pain (IASP) defined chronic CP as "pain that persists beyond normal tissue healing time, which is assumed to be
3 months" [6]. Variations in the definition of CP between and within countries, differences in standards of living and healthcare resources, high prevalence of pain-generating diseases, cultural background, and local traditions can help explain the estimated CP prevalence ranging from $11 \%$ to $55 \%$ $[2,7-9]$. In a recent epidemiological study, CP prevalence in Portugal was estimated at 37\% [10]. CP of moderate to severe intensity has been estimated to occur in 19\% of European adults and $40 \%$ of them reported inadequate management of their pain $[8,11]$. 
$\mathrm{CP}$ is one of the most common reasons why people seek medical care [1]. The economic impact of CP in the USA, in 2008 , ranged from $\$ 560$ to $\$ 635$ billion USD [12]; in Portugal, it was $€ 4611.69$ million (in 2010), corresponding to $2.71 \%$ of the Portuguese annual gross domestic product, with $42.7 \%$ direct and 57.3\% indirect costs [2]. Indirect costs of CP are mainly linked to work absenteeism with reduced levels of productivity and increased risk of leaving the labor market [13].

Ideally, supported by the most recent guidelines for the $\mathrm{CP}$ management, these patients should have access to a multidisciplinary range of diagnostic and therapeutic modalities appropriate to their clinical condition [14-17]. The primary emphasis should be placed on pain management to improve physical and social function and minimize the disability [18-20]. Pain management includes pharmacological therapy, psychological assessment and treatment, invasive techniques, occupational therapy, and rehabilitation medicine $[2,15,20-$ 25]. Interventional Pain Management (IPM) encompasses a wide variety of techniques such as epidural injections [26$29]$, nerve blocks $[18,21,30]$, joint infiltrations [31, 32], spinal cord stimulation $[33,34]$, botulinum toxin application [3537], and radiofrequency denervation [38, 39]. Recent data suggests that some of the IPM techniques allow a superior improvement in physical and functional status of CP patients $[18,25,26,35,38]$, as well as a reduction in associated work absenteeism [18]. Other therapeutic procedures (OTP) are also performed on-site at multidisciplinary chronic pain clinics (MCPC), namely, acupuncture [40-46] and infusion of parenteral drugs [47-49].

In Portugal, there is no available information regarding patterns of prescription of IPM or OTP performed on-site at MCPC. Therefore, as a part of a larger real-world outcomes research prospective cohort study on $\mathrm{CP}$ patients followed at MCPC, this study inquired about the utilization of those techniques and procedures. We aimed at describing quantitatively and qualitatively the patterns of prescription of IPM and OTP performed on-site at MCPC in Portugal.

\section{Methods}

2.1. Selection and Description of Participants. Participants were recruited at their first consultation in four MCPC from the North of Portugal, in the context of a large real-world outcomes research project. The eligible population included adult patients ( $\geq 18$ years old) with chronic noncancer pain lasting more than 3 months (the standard IASP criteria for CP [50]) or with cancer pain regardless of its duration. Patients with psychiatric and/or cognitive impairment, unable to communicate verbally or not fluent in Portuguese were excluded. Participants were followed for twelve months and their clinical records were obtained at baseline and six and 12 months. From all 1343 patients eligible, 808 patients were elected to be part of this study. From these, 139 patients had IPM at least once during the one-year follow-up (Supplement 1 in Supplementary Material available online at https://doi.org/10.1155/2017/8402413).

All participating patients were previously informed of the study objectives and about the data selection and collection procedures, and questions regarding the study, posed by the patients, were properly answered by the research team. All participating patients signed an informed consent form. The study protocol was approved by institutional review boards, ethics committees of the participating hospitals, and CNPD, the Portuguese Data Protection Authority.

2.2. Instruments and Variables. A structured questionnaire was used in baseline interviews. For the purpose of the present study the following data were systematically collected: demographic characteristics, clinical and pain characteristics, and IPM and OTP performed on-site at MCPC prescribed. The Brief Pain Inventory (BPI) [51] which is recommended by consensus groups in the area of measurement and evaluation of pain [52] was used. This instrument was constructed for measuring and evaluating pain in a multidimensional perspective. It includes 15 items evaluating pain presence, severity, location, functional interference, therapeutic strategies, and efficacy of pain management. It is easily applicable, fast, and simple and with very good psychometric properties [53-56]. For the present study, only two constructs were assessed: pain severity and functional interference. Pain severity scale entails four items, maximum, minimum, on average, and at this moment, rated with a numerical scale (0 [no pain] to 10 [the worst pain]) and categorized using Serlin et al. classification [57]. The functional interference scale consists of seven items with numerical rating scale (0 [no interference] to 10 [extreme interference]) that assess pain interference in general activities, mood, mobility, work, personal relationships, sleep, and pleasure to live.

In the descriptive analysis of the sample (all patients) and subsamples (patients with and without IPM), we defined the general characteristics, including sociodemographic (sex, age, educational level, and family support), professional/occupational status, pain characteristics (duration, persistence pattern, location, severity, and interference), general health, and clinical variables (International Statistical Classification of Diseases and Related Health Problems(ICD-) 10 diagnostic classification). The persistence pattern of pain was classified as continuous, pain present every day/always, or discontinuous (recurrent [pain present once to several times/week] and sporadic [pain present less than once to several times/month]).

2.3. Statistical Analysis. Categorical variables were described as absolute $(n)$ and relative (\%) frequencies; continuous variables were described using the median and interquartile ranges considering the tested asymmetric (not normal) distribution or mean and standard deviation otherwise. We used the Chi-square test, or the Fisher's exact test, to test hypotheses for categorical variables. In the case of continuous variables (with asymmetrical distribution) the Mann-Whitney test was used. For all hypothesis tests a significance level of $\alpha=0.05$ was considered. The statistical analysis was performed using the software SPSS v21.0 ${ }^{\circledR}$.

\section{Results}

Table 1 shows the number of patients that were prescribed IPM and/or OTP throughout the study. Considering IPM, 
TABLE 1: Number of patients that received a prescription of interventional pain management and other therapeutic procedures performed on-site at multidisciplinary chronic pain clinics.

\begin{tabular}{|c|c|c|c|c|c|c|c|c|}
\hline \multirow[b]{2}{*}{$\begin{array}{l}\text { IPM and/or OTC } \\
\text { performed on-site }\end{array}$} & \multicolumn{2}{|c|}{$\begin{array}{l}\text { Baseline } \\
(n=808)\end{array}$} & \multicolumn{2}{|c|}{$\begin{array}{l}\text { Six months } \\
(n=801)\end{array}$} & \multicolumn{2}{|c|}{$\begin{array}{l}\text { Twelve months } \\
\quad(n=744)\end{array}$} & \multicolumn{2}{|c|}{$\begin{array}{l}\text { Total throughout the } \\
\text { one-year follow-up } \\
(n=744)\end{array}$} \\
\hline & & & & & & & & \\
\hline Yes & \multicolumn{2}{|c|}{89} & \multicolumn{2}{|c|}{122} & \multicolumn{2}{|c|}{139} & \multicolumn{2}{|c|}{ - } \\
\hline No & \multicolumn{2}{|c|}{719} & \multicolumn{2}{|c|}{679} & \multicolumn{2}{|c|}{605} & \multicolumn{2}{|c|}{-} \\
\hline & $n$ & $\%$ & $n$ & $\%$ & $n$ & $\%$ & $n$ & $\%$ \\
\hline \multicolumn{9}{|l|}{ IPM } \\
\hline Nerve blocks & 39 & 4.8 & 32 & 4.0 & 20 & 2.7 & 88 & 11.8 \\
\hline Viscosupplementation & 18 & 2.2 & 1 & 0.1 & 1 & 0.1 & 16 & 2.2 \\
\hline Radiofrequency & 13 & 1.6 & 11 & 1.4 & 5 & 0.7 & 28 & 3.8 \\
\hline Botulinum toxin & 10 & 1.2 & 2 & 0.2 & 1 & 0.1 & 12 & 1.6 \\
\hline Epidural injections & 9 & 1.1 & 9 & 1.1 & 1 & 0.1 & 17 & 2.3 \\
\hline Neurostimulation & - & - & 1 & 0.1 & - & - & 1 & 0.1 \\
\hline Total & 89 & 11.0 & 56 & 7.0 & 28 & 3.8 & 162 & 21.8 \\
\hline \multicolumn{9}{|l|}{ OTP performed on-site } \\
\hline Acupuncture & 33 & 4.1 & 20 & 2.5 & 12 & 1.6 & 52 & 7.0 \\
\hline Infusions & 21 & 2.6 & 8 & 1.0 & 11 & 1.5 & 31 & 4.2 \\
\hline Mesotherapy & 1 & 0.1 & 1 & 0.1 & - & - & 2 & 0.3 \\
\hline Total & 55 & 6.8 & 29 & 3.6 & 23 & 3.1 & 85 & 11.4 \\
\hline
\end{tabular}

At the top of the table, in each row there is the cumulative number of patients who had interventional pain management and/or other therapeutic procedures prescribed at multidisciplinary chronic pain clinics at each assessment time point. $n$, number of patients at each assessment time point. Furthermore, in each row there are the number of patients $(n)$ and proportions of patients (\%) that were prescribed interventional pain management or other therapeutic procedures performed on-site at multidisciplinary chronic pain clinics at each assessment time point and during the follow-up time. IPM, interventional pain management. OTP, other therapeutic procedures.

nerve blocks were the most frequently prescribed at all time points (39 patients at baseline, 32 patients at 6 months, 20 patients at 12 months, and 88 patients in total throughout the one-year follow-up). On the contrary, botulinum toxin and viscosupplementation were prescribed to a few patients and almost exclusively at baseline. Neuromodulation by neurostimulation was only prescribed to one patient at 6 months. OTP were also prescribed to a considerable number of patients. Among them, acupuncture was prescribed to 52 patients throughout the study, followed by drug infusions to 31 patients.

Sociodemographic characteristics of all patients, patients with IPM, and patients without IPM are described in Table 2. It was observed that $17.2 \%$ of the patients followed in MCPC had IPM prescribed, of which $71.9 \%$ were women and $28.1 \%$ men. Moreover, age was significantly lower in patients with IPM (54.6 (44.0-65.0) versus 59.7 (50.0-71.0) years, $p<$ 0.001 ). Elderly patients (over 75 years) were less frequently prescribed IPM. Patients with IPM were mainly full- or parttime workers while those without IPM were mostly retirees $(p<0.001)$.

Table 3 shows pain clinical characteristics, at the inclusion time in our study, among all patients, patients with IPM, and patients without IPM. Almost $1 / 3$ of the patients with IPM had pain for over 10 years, while almost $90 \%$ of patients with pain duration from 3 to 12 months did not have IPM
( $p=0.006)$. Patients in both groups referred to almost exclusively continuous pain. Significant differences in pain intensity could only be seen for pain at its worst (8.01 without IPM versus 7.23 with IPM; $p=0.003$ ). The location of the pain was heterogeneous and statistically significant differences were found; in all patients that indicated pain in unspecified bones, joints, and muscles $92.1 \%$ were patients without IPM, whereas among all cases of pain in inguinal and pelvic region 31.2\% are reported by patients with IPM $(p=0.047)$. Patients with IPM had significantly lower pain interference score $(p<$ 0001). Specifically, pain-related interference was inferior in general ability $(6.20 \pm 3.26$ versus $7.04 \pm 2.71, p=0.015)$, walking ability $(5.76 \pm 3.81$ versus $6.67 \pm 3.44, p=0.024)$, normal work $(6.09 \pm 3.53$ versus $7.26 \pm 2.82, p<0.001)$, relations with other people $(3.17 \pm 3.64$ versus $4.22 \pm 3.58, p=$ $0.002)$, and enjoyment of life ( $4.18 \pm 3.95$ versus $5.55 \pm 3.79$, $p<0.001)$. More than $57 \%$ of patients who had no pain interference had invasive techniques for pain management, while $88.1 \%$ of patients with severe interference did not had IPM prescribed. In general health no differences were found.

Using the ICD 10 to classify patient's pathologies, 34 diagnoses were obtained from all patients. The five most prevalent diagnoses in patients with IPM were low back pain (28 patients), chronic postoperative pain (16 patients), knee pain (16 patients), pelvic and perineal pain (13 patients), and low back with sciatica (11 patients). We only found five 
TABLE 2: Sociodemographic characteristics of all patients, chronic pain patients with interventional pain management, and chronic pain patients without interventional pain management.

\begin{tabular}{|c|c|c|c|c|c|c|c|c|}
\hline & \multicolumn{2}{|c|}{$\mathrm{All}^{\dagger} \mathrm{CP}$ patients } & \multicolumn{2}{|c|}{$\begin{array}{l}\text { CP patients without } \\
\text { IPM }\end{array}$} & \multicolumn{3}{|c|}{ CP patients with IPM } & \multirow[t]{2}{*}{${ }^{*} p$} \\
\hline & $n$ & $\%$ & $n$ & $\%$ & $n$ & $\%$ & $\mathrm{UF}(\%)$ & \\
\hline \multicolumn{9}{|l|}{ Gender } \\
\hline Male & 265 & 32.8 & 226 & 33.8 & 39 & 28.1 & 14.7 & \multirow{3}{*}{0.199} \\
\hline Female & 543 & 67.2 & 443 & 66.2 & 100 & 71.9 & 18.4 & \\
\hline Total & 808 & 100.0 & 669 & 100.0 & 139 & 100.0 & 17.2 & \\
\hline \multicolumn{9}{|l|}{ Age } \\
\hline $\begin{array}{l}\text { Median } \\
(\mathrm{P} 25-\mathrm{P} 75)\end{array}$ & \multicolumn{2}{|c|}{$\begin{array}{c}60.0 \\
(48.3-70.8) \\
\end{array}$} & \multicolumn{2}{|c|}{$\begin{array}{c}59.7 \\
(50.0-71.0) \\
\end{array}$} & \multicolumn{3}{|c|}{$\begin{array}{c}54.6 \\
(44.0-65.0) \\
\end{array}$} & $<0.001$ \\
\hline \multicolumn{9}{|l|}{ Age categories } \\
\hline $18-24$ years & 9 & 1.1 & 5 & 0.7 & 4 & 2.9 & 44.4 & \multirow{8}{*}{0.010} \\
\hline $25-34$ years & 31 & 3.8 & 21 & 3.1 & 10 & 7.2 & 32.3 & \\
\hline $35-44$ years & 108 & 13.4 & 87 & 13.0 & 21 & 15.1 & 19.4 & \\
\hline $45-54$ years & 164 & 20.3 & 132 & 19.7 & 32 & 23.0 & 19.5 & \\
\hline $55-64$ years & 190 & 23.5 & 156 & 23.3 & 34 & 24.5 & 17.9 & \\
\hline $65-74$ years & 180 & 22.3 & 154 & 23.0 & 26 & 18.7 & 14.4 & \\
\hline 75 years or older & 126 & 15.6 & 114 & 17.0 & 12 & 18.6 & 9.5 & \\
\hline Total & 808 & 100.0 & 669 & 100.0 & 139 & 100.0 & 17.2 & \\
\hline \multicolumn{9}{|l|}{ Family household } \\
\hline Alone & 84 & 10.4 & 69 & 10.3 & 15 & 10.8 & 17.9 & \multirow{7}{*}{0.121} \\
\hline With wife/husband or partner & 317 & 39.2 & 262 & 39.2 & 55 & 39.6 & 17.4 & \\
\hline $\begin{array}{l}\text { With wife/husband or partner } \\
\text { and sons/daughters }\end{array}$ & 244 & 30.2 & 192 & 28.7 & 52 & 37.4 & 21.3 & \\
\hline With sons/daughters & 62 & 7.7 & 54 & 8.1 & 8 & 5.8 & 12.9 & \\
\hline In elderly care homes & 2 & 0.2 & 2 & 0.3 & - & - & - & \\
\hline Other & 99 & 12.3 & 90 & 13.5 & 9 & 6.5 & 9.1 & \\
\hline Total & 808 & 100.0 & 669 & 100.0 & 139 & 100.0 & 17.2 & \\
\hline \multicolumn{9}{|l|}{ Professional/occupational status } \\
\hline Full or part-time worker & 242 & 30.0 & 180 & 26.9 & 62 & 44.6 & 25.6 & \multirow{7}{*}{$<0.001$} \\
\hline Student & 6 & 0.7 & 5 & 0.7 & 1 & 0.7 & 16.7 & \\
\hline Unemployed & 101 & 12.5 & 84 & 12.6 & 17 & 12.2 & 16.8 & \\
\hline $\begin{array}{l}\text { House worker or domestic } \\
\text { worker }\end{array}$ & 33 & 4.1 & 26 & 3.9 & 7 & 5.0 & 21.2 & \\
\hline Retired or preretired & 387 & 47.9 & 342 & 51.1 & 45 & 32.0 & 11.6 & \\
\hline Other & 39 & 4.8 & 32 & 4.8 & 7 & 5.0 & 17.9 & \\
\hline Total & 808 & 100.0 & 669 & 100.0 & 139 & 100.0 & 17.2 & \\
\hline \multicolumn{9}{|l|}{ Education level } \\
\hline No education & 24 & 3.0 & 24 & 4.1 & - & - & - & \multirow{7}{*}{0.195} \\
\hline 1-4 years (basic 1st cycle) & 401 & 49.8 & 330 & 56.4 & 71 & 51.1 & 17.7 & \\
\hline $\begin{array}{l}5-9 \text { years (basic 2nd and 3rd } \\
\text { cycles) }\end{array}$ & 189 & 23.4 & 156 & 26.7 & 33 & 23.7 & 17.5 & \\
\hline 10-12 years (secondary) & 85 & 10.5 & 66 & 11.3 & 19 & 13.7 & 22.4 & \\
\hline More than 12 years (higher) & 86 & 10.7 & 74 & 12.6 & 12 & 8.6 & 14.0 & \\
\hline Other & 21 & 2.6 & 17 & 2.6 & 4 & 2.9 & 19.0 & \\
\hline Total & 806 & 100.0 & 667 & 100.0 & 139 & 100.0 & 17.2 & \\
\hline
\end{tabular}

Each row of the table includes absolute $(n)$ and relative (\%) frequencies of each characteristic and the utilization frequency (\%) of interventional pain management by category (UF). Highlighted in bold are statistically significant results, at a 0.05 significance level. CP, chronic pain. IPM, interventional pain management. P25-P75, 25th percentile and 75 th percentile (representing the interquartile range). ${ }^{*} p$ value for statistical hypothesis tests comparing the subsample of CP subjects with IPM to CP subjects without IPM. Chi-square test or Fisher's exact test for categorical variables and Mann-Whitney test for numerical variables were used. ${ }^{\dagger}$ Chronic pain was defined, using the IASP standard definition, as pain present with duration $\geq 3$ months. 
TABLE 3: Clinical characteristics of all patients, chronic pain patients with interventional pain management, and chronic pain patients without interventional pain management.

\begin{tabular}{|c|c|c|c|c|c|c|c|c|}
\hline \multirow[t]{2}{*}{ Clinical characteristics of pain } & \multicolumn{2}{|c|}{ All ${ }^{\dagger} \mathrm{CP}$ patients } & \multicolumn{2}{|c|}{$\begin{array}{l}\text { CP patients without } \\
\text { IPM } \\
\end{array}$} & \multicolumn{3}{|c|}{ CP patients with IPM } & \multirow[t]{2}{*}{${ }^{*} p$} \\
\hline & $n$ & $\%$ & $n$ & $\%$ & $n$ & $\%$ & UF (\%) & \\
\hline \multicolumn{9}{|l|}{ Duration (categorized) } \\
\hline$\leq 3$ months $-\leq 1$ year & 218 & 27.3 & 196 & 29.7 & 22 & 15.8 & 10.1 & \multirow{6}{*}{0.006} \\
\hline$<1-\leq 2$ years & 110 & 13.8 & 87 & 13.2 & 23 & 16.5 & 20.9 & \\
\hline$<2-\leq 5$ years & 157 & 19.6 & 128 & 19.4 & 29 & 20.9 & 18.5 & \\
\hline$<5-\leq 10$ years & 123 & 15.4 & 103 & 15.6 & 20 & 14.4 & 16.3 & \\
\hline$>10$ years & 191 & 23.9 & 146 & 22.1 & 45 & 32.4 & 23.6 & \\
\hline Total & 799 & 100.0 & 660 & 100.0 & 139 & 100.0 & 17.4 & \\
\hline \multicolumn{9}{|l|}{${ }^{\ddagger}$ Persistence pattern } \\
\hline Continuous & 754 & 93.4 & 626 & 93.7 & 128 & 92.1 & 17.0 & \multirow{3}{*}{0.455} \\
\hline Discontinuous & 53 & 6.6 & 42 & 6.3 & 11 & 7.9 & 20.8 & \\
\hline \multirow[t]{2}{*}{ Total } & 807 & 100.0 & 668 & 100.0 & 139 & 100.0 & 17.2 & \\
\hline & \multicolumn{2}{|c|}{ Mean (SD) } & \multicolumn{2}{|c|}{ Mean (SD) } & \multicolumn{2}{|c|}{ Mean (SD) } & & \\
\hline \multicolumn{9}{|l|}{ Intensity } \\
\hline Pain on average (0-10 NRS) & 5.96 & $(2.13)$ & 6.00 & $(2.01)$ & 5.77 & $(2.50)$ & & 0.641 \\
\hline Pain at its least (0-10 NRS) & 3.63 & $(2.50)$ & 3.63 & $(2.44)$ & 3.63 & $(2.79)$ & & 0.759 \\
\hline Pain at its worst (0-10 NRS) & 7.88 & $(2.11)$ & 8.01 & $(1.98)$ & 7.23 & $(2.61)$ & & 0.003 \\
\hline \multirow[t]{2}{*}{ Pain right now (0-10 NRS) } & 4.83 & $(2.99)$ & 4.88 & $(2.94)$ & 4.58 & $(3.23)$ & & 0.304 \\
\hline & $n$ & $\%$ & $n$ & $\%$ & $n$ & $\%$ & UF (\%) & \\
\hline No pain & 14 & 1.8 & 6 & 0.9 & 8 & 6.2 & 57.1 & \multirow{5}{*}{$<0.001$} \\
\hline${ }^{\S}$ Mild & 229 & 29.4 & 181 & 27.8 & 48 & 37.2 & 21.0 & \\
\hline${ }^{\S}$ Moderate & 244 & 31.3 & 215 & 33.0 & 29 & 22.5 & 11.9 & \\
\hline${ }^{\S}$ Severe & 293 & 37.6 & 249 & 38.2 & 44 & 34.1 & 15.0 & \\
\hline Total & 780 & 100.0 & 651 & 100.0 & 129 & 100.0 & 16.5 & \\
\hline \multicolumn{9}{|l|}{ "Location } \\
\hline Lower limb & 742 & 34.4 & 590 & 33.7 & 152 & 38.7 & 20.5 & \\
\hline Dorsum and lower back & 414 & 19.3 & 343 & 19.6 & 71 & 18.1 & 17.1 & \\
\hline Upper limb & 363 & 16.9 & 288 & 16.4 & 75 & 19.1 & 20.7 & \\
\hline Cervical and facial region & 261 & 12.1 & 224 & 12.8 & 37 & 9.4 & 14.2 & 0.047 \\
\hline Bones/joints/muscles- unspecified & 89 & 4.1 & 82 & 4.7 & 7 & 2.3 & 7.9 & \\
\hline Abdominal and anterior thoracic region & 87 & 4.0 & 78 & 4.4 & 9 & 6.1 & 10.3 & \\
\hline Inguinal and pelvic region & 77 & 3.6 & 53 & 3.0 & 24 & 4.6 & 31.2 & \\
\hline Other & 115 & 5.6 & 97 & 5.5 & 18 & 4.6 & 15.7 & \\
\hline \multirow[t]{2}{*}{ Total } & 2150 & 100.0 & 1757 & 100.2 & 393 & 100.0 & 18.3 & \\
\hline & \multicolumn{2}{|c|}{ Mean (SD) } & \multicolumn{2}{|c|}{ Mean (SD) } & \multicolumn{2}{|c|}{ Mean (SD) } & & \\
\hline \multicolumn{9}{|l|}{ Pain-related interference } \\
\hline General activity & 6.90 & $(2.82)$ & 7.04 & $(2.71)$ & 6.20 & $(3.26)$ & & 0.015 \\
\hline Mood & 6.25 & $(3.28)$ & 6.37 & $(3.21)$ & 5.64 & $(3.58)$ & & 0.054 \\
\hline Walking ability & 6.52 & $(3.51)$ & 6.67 & $(3.44)$ & 5.76 & $(3.81)$ & & 0.024 \\
\hline${ }^{5}$ Normal work & 7.06 & $(2.98)$ & 7.26 & $(2.82)$ & 6.09 & $(3.53)$ & & $<0.001$ \\
\hline Relations with other people & 4.05 & $(3.60)$ & 4.22 & $(3.58)$ & 3.17 & $(3.64)$ & & 0.002 \\
\hline Sleep & 5.64 & $(3.80)$ & 5.72 & $(3.81)$ & 5.20 & $(3.74)$ & & 0.087 \\
\hline Enjoyment of life & 5.33 & $(3.84)$ & 5.55 & $(3.79)$ & 4.18 & $(3.95)$ & & $<0.001$ \\
\hline
\end{tabular}


TABLE 3: Continued.

\begin{tabular}{|c|c|c|c|c|c|c|c|c|}
\hline \multirow[t]{2}{*}{ Clinical characteristics of pain } & \multicolumn{2}{|c|}{$\mathrm{All}^{\dagger} \mathrm{CP}$ patients } & \multicolumn{2}{|c|}{$\begin{array}{l}\text { CP patients without } \\
\text { IPM }\end{array}$} & \multicolumn{3}{|c|}{$\mathrm{CP}$ patients with IPM } & \multirow[t]{2}{*}{${ }^{*} p$} \\
\hline & $n$ & $\%$ & $n$ & $\%$ & $n$ & $\%$ & UF (\%) & \\
\hline \multicolumn{9}{|l|}{${ }^{\mathfrak{E}}$ Interference } \\
\hline No interference & 14 & 1.8 & 6 & 0.9 & 8 & 6.3 & 57.1 & \multirow{5}{*}{$<0.001$} \\
\hline Mild & 229 & 29.4 & 180 & 27.6 & 49 & 38.3 & 21.4 & \\
\hline Moderate & 244 & 31.3 & 208 & 31.9 & 36 & 28.1 & 14.8 & \\
\hline Severe & 293 & 37.6 & 258 & 39.6 & 35 & 27.3 & 11.9 & \\
\hline Total & 780 & 100.0 & 652 & 100.0 & 128 & 100.0 & 16.4 & \\
\hline \multicolumn{9}{|l|}{ General health } \\
\hline Excellent & 13 & 1.6 & 11 & 1.7 & 2 & 1.4 & 15.4 & \multirow{6}{*}{0.082} \\
\hline Very good & 15 & 1.9 & 12 & 1.8 & 3 & 2.2 & 20.0 & \\
\hline Good & 117 & 14.6 & 94 & 14.1 & 23 & 16.5 & 19.7 & \\
\hline Fair & 342 & 42.5 & 271 & 40.8 & 71 & 51.1 & 20.8 & \\
\hline Poor & 317 & 39.4 & 277 & 41.7 & 40 & 28.8 & 12.6 & \\
\hline Total & 804 & 100.0 & 665 & 100.0 & 139 & 100.0 & 17.3 & \\
\hline
\end{tabular}

Each row of the table includes the absolute $(n)$ and relative (\%) frequencies of each characteristic, the utilization frequency (\%) of interventional pain management by category (UF (\%)), and in some cases the mean and standard deviation (SD). Highlighted in bold are statistically significant results, at a 0.05 significance level. CP, chronic pain. IPM, interventional pain management. SD, standard deviation. ${ }^{*} p$ value for statistical hypothesis tests comparing the subsample of CP subjects with IPM to CP subjects without IPM. Chi-square test or Fisher's exact test for categorical variables and Mann-Whitney test for numerical variables were used. ${ }^{\dagger}$ Chronic pain was defined, using the IASP standard definition, as pain present with duration $\geq 3$ months. ${ }^{\ddagger}$ Persistence pattern: continuous - pain present every day/ always; discontinuous - recurrent (pain present once to several times/ week); and sporadic (pain present less than once to several times/month). ${ }^{\S}$ Pain intensity score was categorized taking into account the Serling classification: mild (1-4), moderate (5-6), and severe pain intensity (7-10). "Multiple pain locations were recorded for each patient. ${ }^{9}$ Including both work outside the home and housework. ${ }^{£}$ Pain interference was categorized as mild (1-4), moderate (5-6), and severe pain interference (7-10).

significant differences between patients with and without IPM in what concerns the diagnosis. IPM was only used in $2.8 \%$ of patients with fibromyalgia $(p=0.013)$ and $4.2 \%$ of patients with cancer pain $(p<0.001)$, while it was used in $36.7 \%$ of patients with low back pain with sciatica $(p=0.011)$, $41 \%$ of patients with knee $(p<0.001)$ pain, and $46.4 \%$ of patients with pelvic or perineal pain $(p<0.001)$ (Supplement 2).

Throughout the study 420 treatments were prescribed as seen in Table 4. The most prescribed IPM in all assessment time points was nerve blocks. In one-year follow-up nerve blocks were 108 times prescribed followed by radiofrequency (31 prescriptions) and viscosupplementation (22 prescriptions). The botulinum toxin and viscosupplementation prescriptions were scarce and occurred almost exclusively at baseline. The most prescribed OTP performed on-site at MCPC at baseline were infusions (43 prescriptions) and at 6 and 12 months acupuncture (73 and 45 prescriptions, resp.).

The five most frequent diagnoses of patients that were prescribed each of the IPM and/or OTP are shown in Table 5. IPM was not exclusive to patients with a specific diagnosis. Nerve blocks, epidural, and radiofrequency were extensively used in several diagnoses, and the same occurred with acupuncture. Botulin toxin was prescribed to $69.2 \%$ of patients with pelvic and perineal pain; viscosupplementation was prescribed to $68.4 \%$ of patients diagnosed with knee pain. Considering OTP performed on-site at MCPC, drug infusions were prescribed to $57.9 \%$ of patients with cancer pain.
There was large heterogeneity in the type of treatments and prescription frequency in each MCPC. It is noted that there are techniques only prescribed in some MCPC, such as viscosupplementation, radiofrequency, botulinum toxin, and neurostimulation. One MCPC had only OTP performed onsite (Supplement 3).

\section{Discussion}

There are very few studies focused on IPM utilization patterns in multidisciplinary CP clinics $[17,24]$. To our best knowledge, this is the first study focused on this issue in Portugal and one of the very few elsewhere.

We found that nerve blocks were the most frequent IPM prescribed in MCPC; with a total of 420 IPM or OTP prescribed during the one-year follow-up. A total of 139 patients (17.2\%) in our cohort received IPM for their CP management. Of those, almost $32.4 \%$ had pain for over 10 years and $92.1 \%$ of these reported a continuous pain pattern. There was a diversity of IPM prescribed in the participating MCPC, and botulinum toxin, viscosupplementation, neurostimulation, and radiofrequency were only available in very few centers. In our cohort there is a higher prevalence of women with $\mathrm{CP}$ which is in accordance with the available literature $[10,20$, $58]$, and average pain intensity was approximately 6 in a $0-10$ numerical rating scale.

In general, the success of these techniques is partly dependent on the experience and skill of the provider. There is controversy over the evidence that supports these 
TABLE 4: Prescriptions and rate of prescription of interventional pain management and other therapeutic procedures performed on-site at multidisciplinary chronic pain clinics at baseline, six months, and twelve months and during the whole follow-up period.

\begin{tabular}{|c|c|c|c|c|c|c|c|c|}
\hline & \multicolumn{2}{|c|}{$\begin{array}{l}\text { Baseline } \\
(n t=808)\end{array}$} & \multicolumn{2}{|c|}{$\begin{array}{l}\text { Six months } \\
(n t=801)\end{array}$} & \multicolumn{2}{|c|}{$\begin{array}{l}\text { Twelve months } \\
\quad(n t=744)\end{array}$} & \multicolumn{2}{|c|}{$\begin{array}{l}\text { Total throughout the } \\
\text { one-year follow-up } \\
(n t=744)\end{array}$} \\
\hline & $n$ & Rate & $n$ & Rate & $n$ & Rate & $n$ & Rate \\
\hline \multicolumn{9}{|l|}{$\begin{array}{l}\text { Interventional pain } \\
\text { management }\end{array}$} \\
\hline Nerve blocks & 41 & 5.1 & 51 & 6.4 & 37 & 5.0 & 108 & 14.5 \\
\hline Viscosupplementation & 19 & 2.4 & 6 & 0.7 & 4 & 0.5 & 22 & 3.0 \\
\hline Radiofrequency & 12 & 1.5 & 16 & 2.0 & 5 & 0.7 & 31 & 4.2 \\
\hline Botulinum toxin & 10 & 1.2 & 2 & 0.2 & 3 & 0.4 & 14 & 1.9 \\
\hline Epidural injections & 9 & 1.1 & 11 & 1.4 & 2 & 0.3 & 19 & 2.6 \\
\hline Neurostimulation & - & - & 1 & 0.1 & - & - & 1 & 0.1 \\
\hline Total & 91 & 11.3 & 87 & 10.9 & 51 & 6.9 & 195 & 26.2 \\
\hline \multicolumn{9}{|l|}{ OTP performed on-site } \\
\hline Infusions & 43 & 5.3 & 38 & 4.7 & 25 & 3.4 & 95 & 12.8 \\
\hline Acupuncture & 38 & 4.7 & 73 & 9.1 & 45 & 6.0 & 128 & 17.2 \\
\hline Mesotherapy & 1 & 0.1 & 1 & 0.1 & - & - & 2 & 0.3 \\
\hline Total & 82 & 10.1 & 199 & 14.0 & 70 & 9.4 & 225 & 30.2 \\
\hline
\end{tabular}

Each row of the table includes the number of interventional pain management or other therapeutic procedures performed on-site at multidisciplinary chronic pain clinics at each assessment time point and during the follow-up time $(n)$, the average number of prescriptions per 100 patients at each assessment time point (rate). $n t$, number of patients at each assessment time point. OTP, other therapeutic procedures.

techniques [16], as there is no sufficient data to ascertain the efficacy of some procedures. In some cases, pain relief is only observed during a short period and does not essentially convert into improved function and reduced work absenteeism [59]. Moreover, there is a risk of potential complications associated, but most are transient and often subclinical [30]. IPM techniques have been used for a long time as a last option for patients when all other conservative approaches have failed. Therefore, it is understandable that patients to whom they are actuality prescribed have a much longer reported pain duration [59].

In the present study, IPM were prescribed mainly to patients that did not report significant interference of pain, as measured by the functional interference scale of the Brief Pain Inventory, while the vast majority of patients that reported severe interference were not prescribed IPM. The reasons for these unexpected results are not clear at present, and one can only speculate that patients with severe interference suffered from conditions and/or had a health status (e.g., comorbidities) less likely to be treated by IPM, but additional data is required to investigate this issue.

Among the great variety of IPM used in multidisciplinary pain management $[14,25]$, six techniques plus three OTP performed on-site at MCPC were prescribed in the course of our study.

Nerve blocks, the most frequently prescribed technique in the present study (88 patients), consist in anesthetics delivered to visceral and peripheral nerves in order to interrupt nociceptive input at the source of pain $[16,28]$. This procedure may be understood, especially by patients, as curative, but similarly to other IPM techniques, that is not the case. However, it can be very useful, for instance, to alleviate pain and allow patient to take part in their physical therapy [30].

Viscosupplementation consists of intra-articular injection of hyaluronic acid derivatives. It is one of the more used local treatments for osteoarthritis along with corticosteroid injection. It has been used mainly in knee joint, where it shows moderate and significant pain reduction and increased function [32], but a recent meta-analysis provided no evidence that the effect remains longer than six months [31].

Radiofrequency denervation consists in nerve ablation using heat generated by a radiofrequency current [38]. Facet joints radiofrequency is one of the most prevalent indications for its use with high rates of clinical improvement. However, these effects have also a limited temporal efficacy $[25,39]$.

Botulinum toxin injections as well as acupuncture and dry needling techniques are effective options for myofascial pain, namely, trigger point's deactivation $[36,38]$. However there is no clear evidence about long-term effectiveness of botulinum toxin treatment [35].

Epidural injection was primarily recommended for radicular pain from a herniated disc but could also be performed in patients with spinal stenosis and other low back pain conditions $[25,26]$. Fair evidence of moderate benefit versus placebo injection for short-term low back pain relief was found [27], and even when compared with other pharmacological treatment, epidural injection may be better in some outcomes, but the differences are transient and modest [28]. In fact, epidural steroid injections are the most commonly performed procedure in USA, differing from what we have found in our study, yet evidence is controversial and inconclusive as to their long-term effectiveness $[25,28,29]$. The potential complications associated with neuraxial techniques 
TABLE 5: Characterization of interventional pain management and other therapeutic procedures performed on-site at multidisciplinary chronic pain clinics by the five main diagnoses.

\begin{tabular}{|c|c|c|c|c|c|}
\hline $\begin{array}{l}\text { Interventional pain } \\
\text { management }\end{array}$ & & $I C D$ & 0 diagnostic classificati & & \\
\hline Nerve blocks & Low back pain & $\begin{array}{c}\text { Chronic } \\
\text { postoperative pain }\end{array}$ & $\begin{array}{c}\text { Low back pain with } \\
\text { sciatica }\end{array}$ & Shoulder pain & Cervicalgia \\
\hline $\mathrm{np}(\%)$ & $23(25.7)$ & $14(15.4)$ & $9(9.9)$ & $5(5.5)$ & $5(5.5)$ \\
\hline ni (\%) & $32(20.9)$ & $22(14.4)$ & $12(7.8)$ & $7(4.6)$ & $5(3.3)$ \\
\hline Viscosupplementation & Knee pain & $\begin{array}{c}\text { Unspecified } \\
\text { osteoarthritis, } \\
\text { unspecified site }\end{array}$ & $\begin{array}{c}\text { Chronic } \\
\text { postoperative pain }\end{array}$ & $\begin{array}{c}\text { Pain in unspecified } \\
\text { joint }\end{array}$ & $\begin{array}{l}\text { Low back pain with } \\
\text { sciatica }\end{array}$ \\
\hline $\mathrm{np}(\%)$ & $13(68.4)$ & $3(15.8)$ & $1(5.3)$ & $1(5.3)$ & $1(5.3)$ \\
\hline ni (\%) & $22(75.9)$ & $3(10.3)$ & $1(3.4)$ & $2(6.9)$ & $1(3.4)$ \\
\hline Botulinum toxin & $\begin{array}{l}\text { Pelvic and perineal } \\
\text { pain }\end{array}$ & $\begin{array}{l}\text { Central pain } \\
\text { syndrome }\end{array}$ & $\begin{array}{c}\text { Chronic } \\
\text { postprocedural pain }\end{array}$ & Cancer pain & $\begin{array}{l}\text { Lower abdominal } \\
\text { pain, unspecified }\end{array}$ \\
\hline $\mathrm{np}(\%)$ & $9(69.2)$ & $1(7.7)$ & $1(7.7)$ & $1(7.7)$ & $1(7.7)$ \\
\hline ni (\%) & $11(73.3)$ & $1(6.7)$ & $1(6.7)$ & $1(6.7)$ & $1(6.7)$ \\
\hline Radiofrequency & Low back pain & $\begin{array}{l}\text { Low back pain with } \\
\text { sciatica }\end{array}$ & Shoulder pain & Knee pain & $\begin{array}{c}\text { Other hereditary and } \\
\text { idiopathic } \\
\text { neuropathies } \\
\end{array}$ \\
\hline $\mathrm{np}(\%)$ & $7(25.0)$ & $5(17.9)$ & $3(10.7)$ & $3(10.7)$ & $2(7.1)$ \\
\hline ni (\%) & $9(27.3)$ & $5(15.2)$ & $3(9.1)$ & $3(9.1)$ & $2(6.1)$ \\
\hline Epidural injections & Low back pain & $\begin{array}{c}\text { Low back pain with } \\
\text { sciatica }\end{array}$ & Hip pain & $\begin{array}{c}\text { Chronic } \\
\text { postoperative pain }\end{array}$ & $\begin{array}{l}\text { Radiculopathy, } \\
\text { lumbar region }\end{array}$ \\
\hline $\mathrm{np}(\%)$ & $5(26.3)$ & $4(21.1)$ & $2(10.5)$ & $2(10.5)$ & $2(10.5)$ \\
\hline ni (\%) & $5(22.7)$ & $4(18.2)$ & $2(9.1)$ & $2(9.1)$ & $3(16.6)$ \\
\hline Neurostimulation & $\begin{array}{c}\text { Chronic } \\
\text { postoperative pain }\end{array}$ & & & & \\
\hline $\mathrm{np}(\%)$ & $1(100.0)$ & & & & \\
\hline $\mathrm{ni}(\%)$ & $1(100.0)$ & & & & \\
\hline OTP performed on-site & & $I C D$ & 0 diagnostic classificati & & \\
\hline Infusions & Cancer pain & $\begin{array}{c}\text { Disorders of } \\
\text { trigeminal nerve }\end{array}$ & $\begin{array}{c}\text { Chronic } \\
\text { postoperative pain }\end{array}$ & $\begin{array}{l}\text { Radiculopathy, } \\
\text { lumbar region }\end{array}$ & Cervicalgia \\
\hline $\mathrm{np}(\%)$ & $22(57.9)$ & $4(10.5)$ & $3(7.9)$ & $2(5.3)$ & $2(5.3)$ \\
\hline ni (\%) & $37(45.1)$ & $26(31.7)$ & $5(6.1)$ & $13(15.9)$ & $13(15.9)$ \\
\hline Acupuncture & Low back pain & Cervicalgia & Myalgia & $\begin{array}{c}\text { Pain in unspecified } \\
\text { joint }\end{array}$ & Fibromyalgia \\
\hline $\mathrm{np}(\%)$ & $15(23.1)$ & $11(16.9)$ & $6(9.2)$ & $5(7.7)$ & $5(7.7)$ \\
\hline ni (\%) & $49(30.4)$ & $12(7.5)$ & $27(16.8)$ & $5(3.1)$ & $22(13.7)$ \\
\hline Mesotherapy & Low back pain & $\begin{array}{c}\text { Unspecified } \\
\text { mononeuropathy of } \\
\text { lower limb }\end{array}$ & & & \\
\hline $\mathrm{np}(\%)$ & $1(50.0)$ & $1(50.0)$ & & & \\
\hline ni (\%) & $1(50.0)$ & $1(50.0)$ & & & \\
\hline
\end{tabular}

Each row of the table includes the number of patients and percentage (\%) that were prescribed interventional treatments or other therapeutic procedures performed on-site at multidisciplinary chronic pain clinics (np) and the number and percentage (\%) of prescribed interventional treatments or other therapeutic procedures performed on-site at multidisciplinary chronic pain clinics (ni). ICD, International Statistical Classification of Diseases and Related Health Problems. OTP, other therapeutic procedures.

performance may explain the low prevalence reported on its use.

Neuromodulation is used in some Portuguese MCPC. However, during the recruitment period of our study there was only one patient who was referred to this treatment
[33]. Spinal cord stimulation has formal indication in $\mathrm{CP}$ conditions such as failed back surgery, complex regional pain syndrome, peripheral vascular diseases (Buerger disease, Raynaud syndrome, and limb ischemia I/II), and refractory angina pectoris [34]. 
Taking into consideration OTP performed on-site, prescribed in the MCPC, acupuncture was the most frequently prescribed. Some evidence supports acupuncture effectiveness for chronic low back pain treatment [41], fibromyalgia [42], and neck pain treatment [43]. It is increasingly prescribed [40], but the lack of strong studies that clearly prove its effectiveness has delayed its global recognition [44-46].

Pain is a common symptom in cancer patients. In spite of advances in pain management, effective pain control remains an ongoing challenge, despite high doses of opioids [47]. Drugs infusions can be used safely and should be considered to manage cancer neuropathic pain $[47,48]$. Trigeminal neuralgia is the most common neuralgia in which intravenous infusion of lidocaine may be a therapeutic option when other treatments are ineffective [49]. Thus further investigation will be needed to evaluate clinical significance of infusion therapy [48].

The present findings clarify which and in what extent IPM and OTP performed on-site at MCPC are being prescribed. This study has several strengths, namely, inclusion of several MCPC, a well-structured and detailed questionnaire, telephonic interviews performed systematically, a restricted and trained team, a large sample, and a 12-month followup period. The data presented are unique and to the best of our knowledge there are no similar data in other MCPC that describe their current clinical practice and are useful for comparison and benchmarking.

We have a comprehensive and systematic description of IPM and OTP performed on-site, prescribed, and actually used in MCPC, constituting the clear added value of our study. However, some IPM can be performed for therapeutic or diagnostic purposes and this has not been differentiated in the present study. Further ongoing research will provide data on the evaluation of real-world effectiveness and patient's reported satisfaction by type and timing of techniques performed.

\section{Conclusions}

In Portugal IPM is available in most MCPC, but with marked diversity in the types of techniques and clinical indications. IPM is still seldom prescribed, with only $17.2 \%$ of patients having IPM as part of their management. Future studies focused on patient's reported effectiveness and satisfaction are needed.

\section{Disclosure}

The sponsors did not participate in the design or conduct of this study; in the collection, management, analysis, or interpretation of data; or in the preparation, review, and approval of the manuscripts or decisions to submit for publication. The authors are fully responsible for the contents of the manuscript. The present work was developed as part of the Master Thesis of Dr. Cláudia Gouvinhas presented and approved with honors at the Faculty of Medicine, University of Porto, Portugal, in June 7, 2017 [60].

\section{Conflicts of Interest}

The authors declare that they have no financial or other conflicts of interest.

\section{Acknowledgments}

The authors acknowledge the patients in this study and all healthcare professionals at the participating chronic pain clinics. This work was supported by intramural funds from the Chair on Pain Medicine of the Faculty of Medicine, University of Porto. This work was also partially developed under the scope of project NanoSTIMA (NORTE-01-0145FEDER-000016), which is financed by the North Portugal Regional Operational Programme (NORTE 2020), under the PORTUGAL 2020 Partnership Agreement, and through the European Regional Development Fund (ERDF).

\section{References}

[1] A. M. Elliott, B. H. Smith, K. I. Penny, W. C. Smith, and W. A. Chambers, "The epidemiology of chronic pain in the community," The Lancet, vol. 354, no. 9186, pp. 1248-1252, 1999.

[2] L. F. Azevedo, A. Costa-Pereira, L. Mendonça, C. C. Dias, and J. M. Castro-Lopes, "The economic impact of chronic pain: a nationwide population-based cost-of-illness study in Portugal," European Journal of Health Economics, vol. 17, no. 1, pp. 87-98, 2016.

[3] H. Breivik, E. Eisenberg, and T. O’Brien, “The individual and societal burden of chronic pain in Europe: the case for strategic prioritisation and action to improve knowledge and availability of appropriate care," BMC Public Health, vol. 13, no. 1, article 1229, 2013.

[4] K. F. Stein and A. Miclescu, "Effectiveness of multidisciplinary rehabilitation treatment for patients with chronic pain in a primary health care unit," Scandinavian Journal of Pain, vol. 4, no. 4, pp. 190-197, 2013.

[5] B. H. Smith, A. M. Elliott, W. A. Chambers, W. C. Smith, P. C. Hannaford, and K. Penny, "The impact of chronic pain in the community," Family Practice, vol. 18, no. 3, pp. 292-299, 2001.

[6] IASP, Classification of chronic pain, Seattle: International Association for the Study of Pain, 1994.

[7] R. L. Toblin, K. A. MacK, G. Perveen, and L. J. Paulozzi, "A population-based survey of chronic pain and its treatment with prescription drugs," Pain, vol. 152, no. 6, pp. 1249-1255, 2011.

[8] H. Breivik, B. Collett, V. Ventafridda, R. Cohen, and D. Gallacher, "Survey of chronic pain in Europe: prevalence, impact on daily life, and treatment," European Journal of Pain, vol. 10, no. 4, pp. 287-333, 2006.

[9] K. J. Reid, J. Harker, M. M. Bala et al., "Epidemiology of chronic non-cancer pain in Europe: Narrative review of prevalence, pain treatments and pain impact," Current Medical Research and Opinion, vol. 27, no. 2, pp. 449-462, 2011.

[10] L. F. Azevedo, A. Costa-Pereira, L. Mendonça, C. C. Dias, and J. M. Castro-Lopes, "Epidemiology of chronic pain: A population-based nationwide study on its prevalence, characteristics and associated disability in Portugal," Journal of Pain, vol. 13, no. 8, pp. 773-783, 2012.

[11] R. Sinatra, "Causes and consequences of inadequate management of acute pain," Pain Medicine, vol. 11, no. 12, pp. 1859-1871, 2010. 
[12] D. Gaskin and P. Richard, "The Economic Costs of Pain in the United States. Washington: Institute of Medicine (US) Committee on Advancing Pain Research, Care, and Education. Relieving Pain in America: A Blueprint for Transforming Prevention, Care, Education, and Research," 2011.

[13] C. Phillips, "The Cost and Burden of Chronic Pain," Reviews in Pain, vol. 3, no. 1, pp. 2-5, 2009.

[14] J. Guzmán, R. Esmail, K. Karjalainen, A. Malmivaara, E. Irvin, and C. Bombardier, "Multidisciplinary rehabilitation for chronic low back pain: systematic review," The British Medical Journal, vol. 322, no. 7301, pp. 1511-1516, 2001.

[15] D. R. Fitzgibbon, K. L. Posner, K. B. Domino, R. A. Caplan, L. A. Lee, and F. W. Cheney, "Chronic Pain Management: American Society of Anesthesiologists Closed Claims Project," Anesthesiology, vol. 100, no. 1, pp. 98-105, 2004.

[16] S. Vasudevan, Multidisciplinary Management of Chronic Pain-A Practical Guide for Clinicians, Springer, Cham, Switzerland, 2015.

[17] R. Dale and B. Stacey, "Multimodal Treatment of Chronic Pain," Medical Clinics of North America, vol. 100, no. 1, pp. 55-64, 2016.

[18] L. Manchikanti, V. Pampati, C. E. Bakhit et al., "Effectiveness of lumbar facet joint nerve blocks in chronic lower back pain: A randomized clinical trial," Pain Physician, vol. 4, no. 1, pp. 101117, 2001.

[19] "Management of Chronic Pain Syndromes: Issues and Interventions," Pain Medicine, vol. 6, 1, pp. S1-S21, 2005.

[20] M. J. McAllister, K. E. McKenzie, D. M. Schultz, and M. G. Epshteyn, "Effectiveness of a multidisciplinary chronic pain program for treatment of refractory patients with complicated chronic pain syndromes," Pain Physician, vol. 8, no. 4, pp. 369$373,2005$.

[21] Z. Zhao and D. Cope, "Nerve blocks, trigger points, and intrathecal therapy for chronic pain," in Handbook of Pain and Palliative Care Rockville, R. Moore, Ed., pp. 550-556, Springer, Berlin, Germany, 2013.

[22] J. Garcia and R. D. Altman, "Chronic pain states: Invasive procedures," Seminars in Arthritis and Rheumatism, vol. 27, no. 3, pp. 156-160, 1997.

[23] R. S. Roth, M. E. Geisser, and D. A. Williams, "Interventional pain medicine: Retreat from the biopsychosocial model of pain," Translational Behavioral Medicine, vol. 2, no. 1, pp. 106-116, 2012.

[24] M. A. Ashburn and P. S. Staats, "Management of chronic pain," The Lancet, vol. 353, no. 9167, pp. 1865-1869, 1999.

[25] H. Smith, Y. Youn, R. C. Guay, A. Laufer, and J. G. Pilitsis, “The Role of Invasive Pain Management Modalities in the Treatment of Chronic Pain," Medical Clinics of North America, vol. 100, no. 1, pp. 103-115, 2016.

[26] J.-P. Valat and S. Rozenberg, "Local corticosteroid injections for low back pain and sciatica," Joint Bone Spine, vol. 75, no. 4, pp. 403-407, 2008.

[27] R. Chou, J. D. Loeser, D. K. Owens et al., "Interventional therapies, surgery, and interdisciplinary rehabilitation for low back pain: an evidence-based clinical practice guideline from the American pain society," Spine, vol. 34, no. 10, pp. 1066-1077, 2009.

[28] S. P. Cohen, S. Hanling, M. C. Bicket et al., "Epidural steroid injections compared with gabapentin for lumbosacral radicular pain: Multicenter randomized double blind comparative efficacy study," BMJ (Online), vol. 350, Article ID h1748, 2015.
[29] S. P. Cohen, S. Hayek, Y. Semenov et al., "Epidural steroid injections, conservative treatment, or combination treatment for cervical radicular pain: A multicenter, randomized, comparativeeffectiveness study," Anesthesiology, vol. 121, no. 5, pp. 1045-1055, 2014.

[30] C. L. Jeng, T. M. Torrillo, and M. A. Rosenblatt, "Complications of peripheral nerve blocks," British Journal of Anaesthesia, vol. 105, 1, pp. i97-i107, 2010.

[31] P. Jüni, R. Hari, A. W. S. Rutjes et al., "Intra-articular corticosteroid for knee osteoarthritis," The Cochrane database of systematic reviews, vol. 10, p. CD005328, 2015.

[32] V. Legré-Boyer, "Viscosupplementation: techniques, indications, results," Orthopaedics and Traumatology: Surgery and Research, vol. 101, no. 1, pp. S101-S108, 2015.

[33] J. Cortez, F. Monteiro, M. J. Ramalho, J. M. Paulo, and J. S. Duarte, "Angor e Neuroestimulação Medular," Dor, vol. 13, no. 2, pp. 24-26, 2005.

[34] T. R. Deer, N. Mekhail, D. Provenzano et al., “The appropriate use of neurostimulation of the spinal cord and peripheral nervous system for the treatment of chronic pain and ischemic diseases: The neuromodulation appropriateness consensus committee," Neuromodulation, vol. 17, no. 6, pp. 515-550, 2014.

[35] S. Patil, O. Willett, T. Thompkins et al., "Botulinum Toxin: Pharmacology and Therapeutic Roles in Pain States," Current Pain and Headache Reports, vol. 20, no. 3, article no. 15, pp. 1-8, 2016.

[36] R. Kermen, "Botulinum toxin for chronic pain conditions," Disease-a-Month, vol. 62, no. 9, pp. 353-357, 2016.

[37] P. H. Hawley, "Botulinum toxin for severe anorectal pain," Journal of Pain and Symptom Management, vol. 24, no. 1, pp. 11-13, 2002.

[38] R. Chou, S. J. Atlas, S. P. Stanos, and R. W. Rosenquist, "Nonsurgical interventional therapies for low back pain: A review of the evidence for an American pain society clinical practice guideline," Spine, vol. 34, no. 10, pp. 1078-1093, 2009.

[39] L. Manchikanti, J. A. Hirsch, F. J. E. Falco, and M. V. Boswell, "Management of lumbar zygapophysial (facet) joint pain," World Journal of Orthopaedics, vol. 7, no. 5, pp. 315-337, 2016.

[40] J. Wilkinson and R. Faleiro, "Acupuncture in pain management," Continuing Education in Anaesthesia, Critical Care \& Pain, vol. 7, no. 4, pp. 135-138, 2007.

[41] E. Manheimer, A. White, B. Berman, K. Forys, and E. Ernst, "Meta-analysis: acupuncture for low back pain," Annals of Internal Medicine, vol. 142, no. 8, pp. 651-663, 2005.

[42] J. Vas, K. Santos-Rey, R. Navarro-Pablo et al., "Acupuncture for fibromyalgia in primary care: A randomised controlled trial," Acupuncture in Medicine, vol. 34, no. 4, pp. 257-266, 2016.

[43] H. MacPherson, H. Tilbrook, S. Richmond et al., "Alexander technique lessons or acupuncture sessions for persons with chronic neck pain: A randomized trial," Annals of Internal Medicine, vol. 163, no. 9, pp. 653-662, 2015.

[44] A. J. Vickers and K. Linde, "Acupuncture for chronic pain," Journal of the American Medical Association, vol. 311, no. 9, pp. 955-956, 2014.

[45] D. C. Turk, H. D. Wilson, and A. Cahana, "Treatment of chronic non-cancer pain,” The Lancet, vol. 377, no. 9784, pp. 2226-2235, 2011.

[46] J. Ezzo, B. Berman, V. A. Hadhazy, A. R. Jadad, L. Lao, and B. B. Singh, "Is acupuncture effective for the treatment of chronic pain? A systematic review," Pain, vol. 86, no. 3, pp. 217-225, 2000. 
[47] S. C. Chia, A. Hum, W. Y. Ong, and A. Lee, "Parenteral lignocaine in cancer neuropathic pain: A series of case reports," Progress in Palliative Care, vol. 22, no. 5, pp. 253-257, 2014.

[48] B. Kosharskyy, W. Almonte, N. Shaparin, M. Pappagallo, and H. Smith, "Intravenous infusions in chronic pain management," Pain Physician, vol. 16, no. 3, pp. 231-249, 2013.

[49] E. Stavropoulou, E. Argyra, P. Zis, A. Vadalouca, and I. Siafaka, "The Effect of Intravenous Lidocaine on Trigeminal Neuralgia: A Randomized Double Blind Placebo Controlled Trial," ISRN Pain, vol. 2014, pp. 1-5, 2014.

[50] A. M. Harvey, "Classification of Chronic Pain-Descriptions of Chronic Pain Syndromes and Definitions of Pain Terms," The Clinical Journal of Pain, vol. 11, no. 2, p. 163, 1995.

[51] C. Cleeland and K. Ryan, "Pain assessment: global use of the Brief Pain Inventory," Annals of the Academy of Medicine, vol. 23, no. 2, pp. 129-138, 1994.

[52] A. Caraceni, N. Cherny, R. Fainsinger et al., "Pain measurement tools and methods in clinical research in palliative care: recommendations of an Expert Working Group of the European Association of Palliative Care," Journal of Pain and Symptom Management, vol. 23, no. 3, pp. 239-255, 2002.

[53] C. S. Cleeland, R. Gonin, A. K. Hatfield et al., "Pain and its treatment in outpatients with metastatic cancer," New England Journal of Medicine, vol. 330, no. 9, pp. 592-596, 1994.

[54] S. Keller, C. M. Bann, S. L. Dodd, J. Schein, T. R. Mendoza, and C. S. Cleeland, "Validity of the brief pain inventory for use in documenting the outcomes of patients with noncancer pain," The Clinical Journal of Pain, vol. 20, no. 5, pp. 309-318, 2004.

[55] G. Tan, M. P. Jensen, J. I. Thornby, and B. F. Shanti, "Validation of the brief pain inventory for chronic nonmalignant pain," Journal of Pain, vol. 5, no. 2, pp. 133-137, 2004.

[56] C. Cleeland, "Measurement of pain by subjective report," in Advances in Pain Research and Therapy, C. Hapman and J. D. Loeser, Eds., vol. 12, pp. 391-403, Raven Press, New York, NY, USA, 1989.

[57] R. C. Serlin, T. R. Mendoza, Y. Nakamura, K. R. Edwards, and C. S. Cleeland, "When is cancer pain mild, moderate or severe? Grading pain severity by its interference with function," Pain, vol. 61, no. 2, pp. 277-284, 1995.

[58] B. H. Smith, J. L. Hopton, and W. Alastair Chambers, "Chronic pain in primary care," Family Practice, vol. 16, no. 5, pp. 475-482, 1999.

[59] J. Loeser, "Multidisciplinary pain management," in The Paths of Pain 1975-2005, H. L. J. Merskey and R. Dubner, Eds., pp. 503511, IASP Press, Seattle, Wash, USA, 2005.

[60] C. Gouvinhas, Interventional pain management in multidisciplinary chronic pain clinics - A prospective multicenter cohort study with one year follow-up [M.S. thesis], Faculty of Medicine of the University of Porto, Porto, Portugal, 2017. 


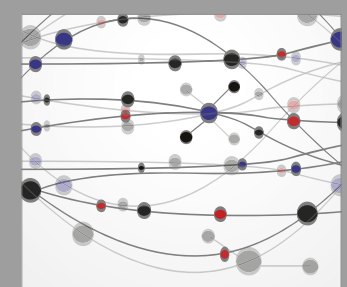

The Scientific World Journal
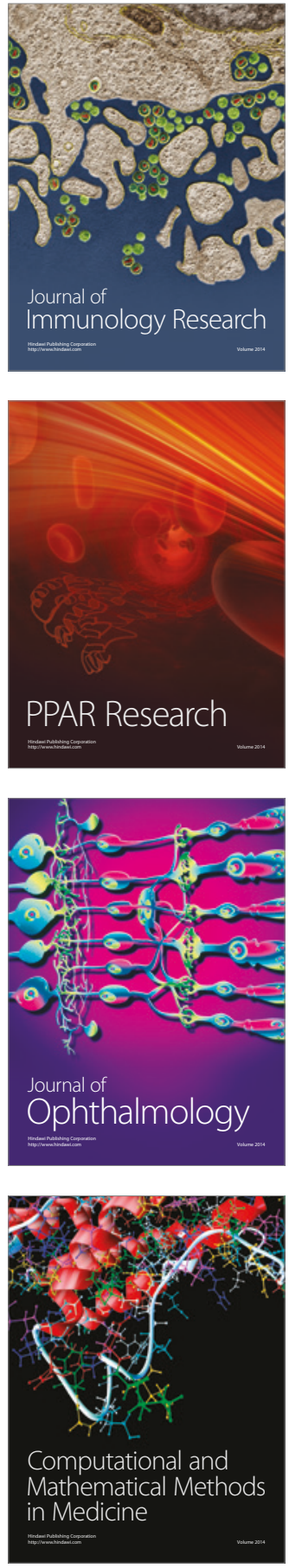

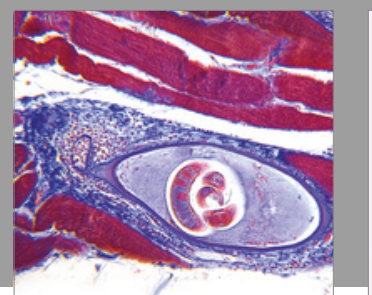

Gastroenterology Research and Practice
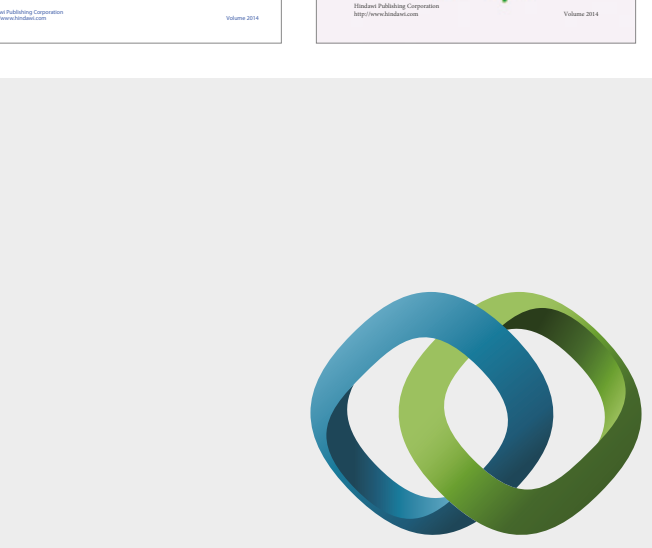

\section{Hindawi}

Submit your manuscripts at

https://www.hindawi.com
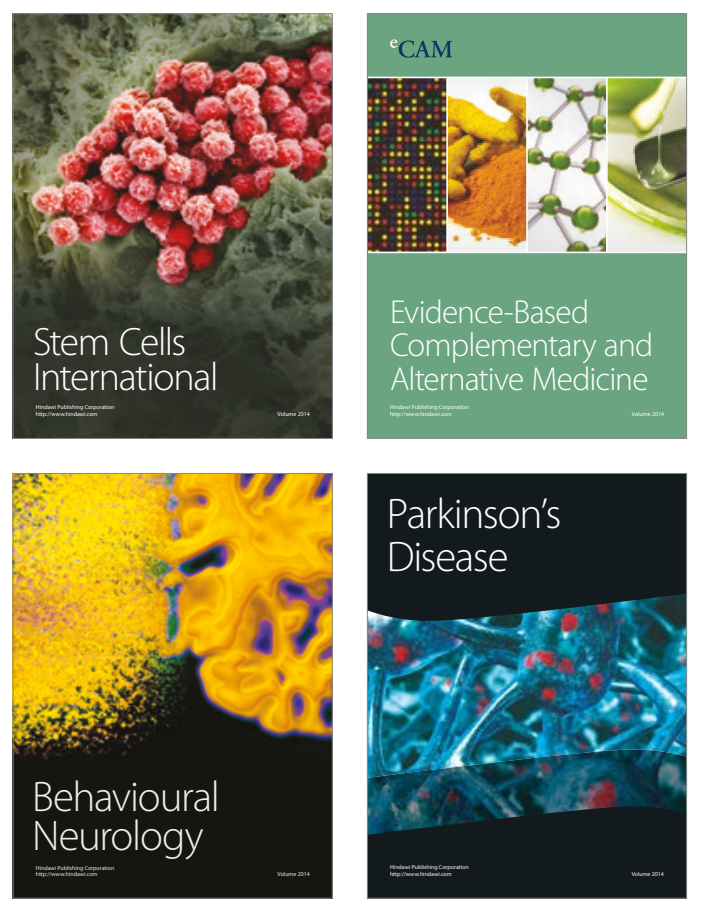
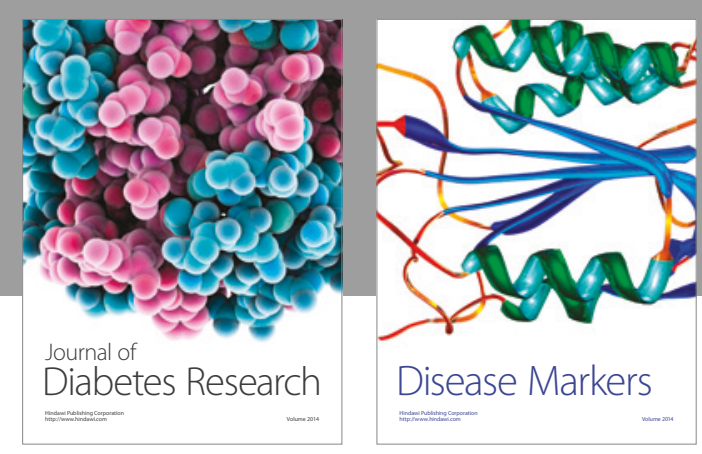

Disease Markers
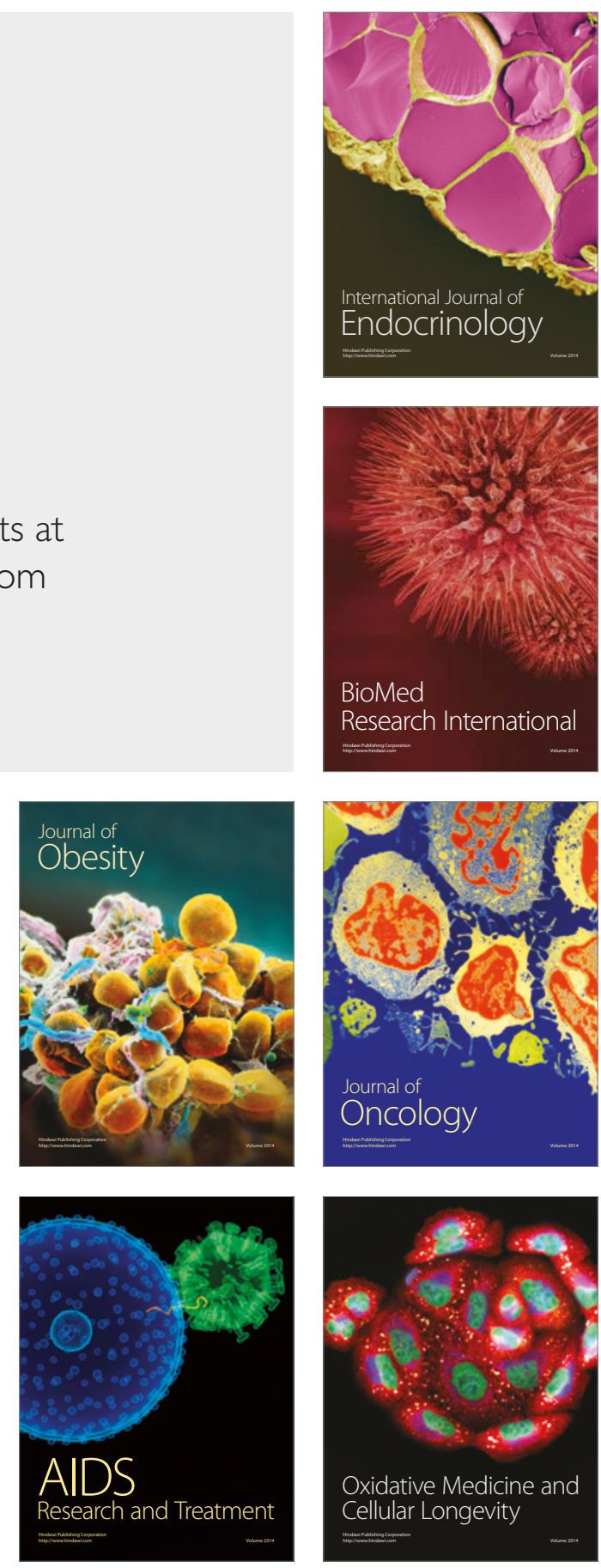